\title{
Diferencial de salários da mão de obra terceirizada no Brasil •
}

\author{
Guilherme Stein \\ Pesquisador de Economia - Fundação de Economia e Estatística Siegfried Emanuel Heuser \\ Endereço: Rua Duque de Caxias, 1691/808 - Porto Alegre - Rio Grande do Sul/RS \\ CEP: 90010-283 - E-mail: guilherme.stein@fee.tche.br
}

\section{Eduardo Zylberstajn}

Professor - Escola de Economia de São Paulo - Fundação Getúlio Vargas (EESP-FGV)

Endereço: Rua Itapeva, 474, $5^{\circ}$ andar - São Paulo/SP

CEP: 01332-000 - E-mail: eduardo.zylberstajn@fgv.br

\section{Hélio Zylberstajn}

Professor - Universidade de São Paulo (USP)

Endereço: Av. Professor Luciano Gualberto, 908, FEA 1 - Cidade Universitária - São Paulo/SP

CEP: 05508-010 - E-mail: hzy@usp.br

Recebido: 06/08/2015. Aceite: 07/05/2017.

\section{Resumo}

Este artigo compara os salários da mão de obra terceirizada no Brasil com os dos trabalhadores contratados diretamente pelas empresas. A comparação simples entre as remunerações médias dos dois grupos indica que os salários dos terceirizados são $17 \%$ inferiores, mas quando o diferencial é controlado pelo efeito fixo do trabalhador, a diferença cai para 3,6\%. Além disso, as evidências apontam para uma grande heterogeneidade no diferencial salarial. Trabalhadores de ocupações como telemarketing têm o salário médio 8\% inferior quando estão terceirizados. Por outro lado, ocupações como segurança e vigilância oferecem salários estatisticamente maiores, em média, para os terceirizados. As evidências indicam ainda que o diferencial desfavorável ao terceirizado apresentou um aumento entre 2007 e 2012 e uma redução a partir de então.

\section{Palavras-Chave}

Mercado de trabalho. Terceirização. Diferenciais salariais.

\begin{abstract}
This paper estimates the wage differentials between outsourced and in-house workers in Brazil. The simple comparison of average wages of the two groups indicates that outsourced workers earn $17 \%$ less, but after controlling by workers fixed effects, the difference drops to $3.6 \%$. In addition, we show that there is great heterogeneity in the wage differential. Telemarketing workers earn $8 \%$ less when outsourced. On the other hand, occupations such as security and surveillance offer statistically higher wages, on average, to outsourced workers. The evidence also indicates that the unfavorable differential to the outsourced showed an increase between 2007 and 2012 and a decrease after then.

- Os autores agradecem os comentários de André Portela Souza, Cristine Pinto, Naércio Menezes-Filho, Reynaldo Fernandes e Vladimir Ponczek. Quaisquer erros permanecem sendo responsabilidade exclusiva dos autores. O código-fonte usado para preparo da base de dados e estimação dos resultados está disponível nos endereços https://sites.google.com/site/ezylberstajn ou https://sites.google.com/site/ steinguilherme.
\end{abstract}




\section{Keywords}

Labor Market. Outsourcing. Wage Differentials.

\section{JEL Classification}

J310. J010. J400.

\section{Introdução}

Por que e sob quais circunstâncias o processo produtivo é organizado por firmas? Coase (1937) respondeu a essa pergunta há 80 anos, chamando a atenção para os custos de transação. Nessas oito décadas, houve mudanças tecnológicas e sociais profundas (internet, transporte, logística etc.) que estão reorganizando o trabalho no mundo (Eichhorst 2015 e Zimmerman 2015). A teoria de Coase continua válida, mas certamente mudaram os custos de transação que fazem ou faziam com que a coordenação da produção fosse mais eficiente sob um empreendedor do que sob o sistema de preços. Nesse sentido, observamos atualmente novas formas de organização do trabalho e da produção (Eurofound 2015) e em muitos casos a verticalização das firmas dá lugar a redes horizontais de produção.

No Brasil, a forma mais comum de observarmos essa "horizontalização" da produção é através da terceirização, termo utilizado para caracterizar uma situação em que uma firma transfere parte de suas atividades para outra. Nesses casos, observa-se frequentemente em debates políticos e técnicos o questionamento acerca da chamada "precarização" do trabalho, na qual os trabalhadores recebem remunerações menores e têm piores condições de trabalho em comparação a seus pares diretamente contratados pelas firmas.

Teoricamente, só haveria motivo para encontrarmos diferenças salariais entre terceirizados e trabalhadores diretamente contratados para uma mesma tarefa caso o mercado de trabalho terceirizado fosse de alguma forma segmentado. Do contrário (mobilidade perfeita dos trabalhadores), os salários deveriam ser equivalentes por conta da possibilidade de arbitragem. Ou seja, é difícil explicar teoricamente porque um terceirizado aceitaria ganhar menos nessa condição, a menos que haja diferenças em aspectos institucionais ou no perfil dos empregados que fossem relevantes para a formação dos salários. Exemplos desses aspectos institucionais seriam, entre outros, a representação sindical ou a insegurança jurídica que faria 
com que a contratante exigisse um "desconto" para contratar terceirizados em antecipação a uma eventual ação judicial. Exemplos de diferenças no perfil dos empregados seriam questões como habilidade, experiência ou escolaridade, que podem estar correlacionados com a autosseleção dos empregados em um tipo de mercado ou outro.

A legislação trabalhista no Brasil foi omissa em relação à terceirização desde a promulgação da Constituição de 1988. Para suprir essa lacuna, o Tribunal Superior do Trabalho formulou a Súmula 331/1993, que define que as empresas podem terceirizar "serviços de vigilância e de conservação e limpeza, ou outros serviços especializados ligados à atividade-meio do tomador, desde que inexistente a pessoalidade e a subordinação direta". A preocupação em proibir a terceirização mais ampla parece estar ligada à ideia de que de alguma forma a terceirização implica a contratação dos trabalhadores em condições piores do que eles teriam caso fossem contratados diretamente. Apenas em 2017, o Congresso Nacional aprovou uma legislação que regulamenta e permite a terceirização irrestrita no país.

Apesar disso, não existem no Brasil estudos empíricos que avaliam o diferencial de salários e de condições de trabalho dos trabalhadores terceirizados e próprios. ${ }^{l}$ Idealmente, para responder se há diferenças salariais entre as duas formas de contratação, seria necessário observar o mesmo trabalhador sendo contratado pela mesma empresa na condição de próprio e na condição de terceiro, ao mesmo tempo. Como isso não é possível no mundo real, estudos empíricos adotam estratégias que tentam tornar comparáveis os salários observados por diferentes tipos de trabalhadores. Uma primeira abordagem seria a comparação simples entre os salários médios dos terceirizados e dos próprios, como proposto em CUT (2014). ${ }^{2}$ Entretanto, essa abordagem desconsidera as diferenças nas características tanto dos trabalhadores quanto das firmas que os contratam. Por exemplo, é possível que no início de carreira seja mais comum que um vigia seja contratado por uma empresa que presta serviços de vigilância e que, depois de adquirir certa experiência, esse vigia seja contratado diretamente. Também é possível que as empresas que terceirizam sejam intrinsicamente diferentes das empresas que contratam diretamente, necessitando de trabalhadores mais

1 Neste trabalho nos referimos a trabalhadores contratados diretamente como 'trabalhadores próprios', sendo que o termo próprio não é empregado no sentido de propriedade, mas sim, de acordo com as definições usuais encontradas nos dicionários, no sentido de que o contrato de trabalho é inerente e característico da firma tomadora dos serviços.

2 Na verdade, o estudo citado não compara médias salariais de trabalhadores terceirizados. A comparação é ainda mais simples, entre ocupações tipicamente terceirizadas e as demais ocupações. 
ou menos qualificados. Por exemplo, um prédio que contrata diretamente uma faxineira pode demandar características (observáveis ou não observáveis) diferentes das demandadas por prédios que terceirizam esse trabalho.

Para tentar expurgar essas diferenças, uma abordagem alternativa compararia os salários médios dos terceirizados e dos não terceirizados, controlando pelas características observáveis das firmas e dos trabalhadores. Fatores como escolaridade, idade e ramo de atividade explicam, como veremos, parte da diferença de remuneração entre os dois tipos de contratação. Controlando por essas características, notamos que no Brasil os trabalhadores terceirizados ganharam, em média, 18\% menos que os trabalhadores próprios no período de 2007 a 2014. Porém, mesmo o controle das características observáveis pode ser um exercício incompleto se, além delas, aspectos não observáveis também forem relevantes para a determinação do salário. Habilidades não cognitivas são relevantes para a determinação da remuneração do trabalhador, como, por exemplo, motivação, confiabilidade, dedicação, capacidade de comunicação e maturidade emocional (Heckman e Rubenstein 2001; Heckman, Stixrud e Urzua 2006). Essas habilidades podem ser valorizadas pelos empregadores, mas não são facilmente observadas pelos pesquisadores. Além disso, é possível que algumas dessas características sejam mais comumente encontradas nos trabalhadores próprios ou nos terceirizados. Dessa forma, a comparação dos salários médios controlada pelas características observáveis também não seria suficiente para a correta medida do diferencial de salários.

Diferenciais salariais já foram amplamente discutidos na literatura nacional (ver, por exemplo, Botelho e Ponczek 2011 e Menezes-Filho et al. 2004), mas mesmo com nossos melhores esforços não encontramos estudos empíricos que discutam a questão do impacto da terceirização nos salários no Brasil. Nos EUA, Duble e Kaplan (2010) é um raro exemplo de estudo empírico nos moldes deste artigo, com uma modelagem de efeito fixo. Os autores encontram um diferencial de $-4 \%$ para serviços de limpeza e de $-9 \%$ para vigias terceirizados. Essas evidências apontam para impactos heterogêneos da terceirização.

Este estudo busca chegar o mais próximo possível do exercício hipotético citado acima. Conseguimos observar o mesmo indivíduo sob duas formas de contratação, mas não no mesmo momento e na mesma firma. Utilizando dados em painel, observamos o mesmo trabalhador ao longo do tempo e conseguimos comparar as mudanças em seu próprio salário, de acordo com 
a forma de contratação. Não observamos dois salários ao mesmo tempo e nem na mesma firma, mas conseguimos controlar as comparações através dos chamados efeitos fixos dos trabalhadores. Com essa metodologia, mostramos que para um conjunto de seis ocupações tipicamente terceirizáveis no Brasil o diferencial de salários dos trabalhadores terceirizados é de $-3,6 \%$. Mais ainda, mostramos que esse diferencial é bastante heterogêneo: enquanto serviços como Limpeza ou Telemarketing têm um diferencial negativo para os terceirizados, a terceirização de serviços de Segurança/ Vigilância implica uma remuneração média maior do que a recebida pelos diretamente contratados.

Essas evidências são importantes para embasar o debate acerca da regulamentação da terceirização no Brasil. Em 1998, o Senado Federal aprovou projeto de lei que autorizava a terceirização irrestrita no país para que, apenas em 2017, quase duas décadas depois, a Câmera dos Deputados o aprovasse definitivamente. Além disso, em 2015, a mesma Câmara dos Deputados aprovou o Projeto de Lei 4.330, que autoriza a terceirização para todas as atividades da empresa e estabelece as regras para que esse procedimento possa ser adotado. O projeto foi ao Senado e atualmente encontra-se em discussão na casa. Diante do aquecido debate que se estabelece na sociedade brasileira, buscamos contribuir mostrando evidências dos efeitos da terceirização nos salários dos trabalhadores.

O restante do trabalho está organizado da seguinte forma. A seção 2 traz uma breve discussão teórica sobre a terceirização da mão de obra. A seção 3 descreve a base de dados utilizada, enquanto a seção 4 descreve e explica a estratégia empírica. Os resultados são apresentados na seção 5. A seção 6 faz uma síntese e apresenta as considerações finais.

\section{Terceirização da mão de obra: aspectos teóricos}

Dois textos clássicos na literatura econômica, utilizados por Zylberstajn (2015) para refletir sobre as transformações do mercado de trabalho, podem balizar a discussão teórica sobre a terceirização da mão de obra no Brasil. O primeiro, de Becker (1961), propõe a distinção entre conhecimento geral e conhecimento específico. Becker utilizou essa dicotomia para discutir os diferenciais salariais atribuíveis à produtividade, no con- 
texto teórico do modelo do capital humano. Os dois tipos de conhecimento, uma vez adquiridos, aumentam a produtividade do trabalhador. A dicotomia é usada para diferenciar entre conhecimento com mercado (o conhecimento geral) e conhecimento sem mercado (o específico). Para a discussão do tema da terceirização, é importante ressaltar a implicação da existência dos dois tipos de conhecimento: nas empresas em que predomina o conhecimento geral, o vínculo de emprego é mais tênue e a rotatividade é maior, porque os trabalhadores competem pelas oportunidades existentes no mercado externo à firma. Por outro lado, onde o conhecimento específico predomina, o compromisso entre trabalhador e empresa é mais forte e a duração dos vínculos maior, para que o investimento recíproco na aquisição do conhecimento possa retornar aos dois investidores. Nesses casos, as oportunidades alternativas são pouco atraentes para os trabalhadores, pois sua produtividade fora da firma seria menor. $\mathrm{O}$ mercado para seu trabalho se resume à firma onde adquiriu e onde utiliza o conhecimento específico.

O segundo autor, Coase (1937), oferece uma reflexão sobre as fronteiras da firma. Coase se pergunta inicialmente por que e sob quais circunstâncias o processo produtivo é organizado por firmas e cria o conceito de custos de transação para responder. O autor argumenta que a firma é um arranjo eficiente para reduzir os custos de transação e coordenação da produção. Sua conclusão sobre as fronteiras da firma é ao mesmo tempo simples e fundamental: a firma deixa de ampliar suas fronteiras quando os custos de coordenação ficam maiores que os custos de comprar fora dos seus limites. Naquela época (anos 1930 do século passado), era eficiente organizar a produção por meio de estruturas verticalizadas, geridas por meio de relações hierárquicas e burocráticas. Dessa forma, Coase explicou a emergência e a preponderância da grande corporação característica do capitalismo do século passado.

A dicotomia do conhecimento de Becker e o conceito de custos de transação e de coordenação de Coase são duas faces da mesma moeda. A empresa verticalizada, gigantesca e burocrática é eficiente somente se conseguir organizar relações estáveis com fornecedores e clientes e, principalmente, com os empregados. E relações estáveis com empregados precisam de ambientes confiáveis, reputação preservada, idiossincrasias na gestão e na forma de produzir, ou seja, de conhecimento específico à firma. 
A partir dos anos 1990, surgiram mudanças tecnológicas e sociais profundas (internet, comunicações, transporte, logística etc.) que estão reorganizando o trabalho no mundo (Eichhorst 2015 e Zimmerman 2015). Certamente mudaram os custos de transação que fazem ou faziam com que a coordenação da produção fosse mais eficiente sob a coordenação de um empreendedor do que sob a coordenação do sistema de preços. Nesse sentido, observamos novas formas de organização do trabalho e da produção e em muitos casos a verticalização das firmas dá lugar a redes horizontais de produção.

Os conceitos de Becker e de Coase continuam válidos e continuam nos ajudando a explicar e entender o mercado de trabalho do novo século. As fronteiras da firma continuam sendo determinadas pelo custo de produzir ou comprar fora. $\mathrm{O}$ conhecimento exigido dos trabalhadores continua a ter duas dimensões, o específico e o geral. Ocorre que hoje os custos de transação e de coordenação são muito menores. A produção pode ser organizada e coordenada horizontalmente por meio de redes de relacionamentos, as cadeias produtivas de dimensões globais. Em muitos casos não há mais necessidade de verticalizar a firma; pelo contrário, é mais eficiente horizontalizar a produção. A cadeia produtiva vertical em uma única grande corporação é menos competitiva do que a cadeia produtiva horizontal, de parceiros globais. E na firma global, horizontal e talvez até mesmo virtual, que é a vencedora de hoje, não há a predominância do conhecimento específico. As empresas de hoje são muito parecidas e menos idiossincráticas. Coase e Becker ainda explicam o mercado de trabalho e seus conceitos nos ajudam a entender porque o emprego permanente e a carreira em uma única empresa típicos do século passado estão sendo substituídos por relações de trabalho mais efêmeras e por carreiras que são trajetórias em diferentes empresas ao longo do ciclo de vida profissional.

Essas mudanças nas cadeias produtivas levam a um fenômeno conhecido internacionalmente como outsourcing. No Brasil, esse termo ficou conhecido como terceirização, que nada mais é do que a transferência de parte das atividades de uma firma para outra. O outsourcing só ocorrerá se houver alguma vantagem de custo para a firma que terceiriza sua mão de obra. Essa vantagem pode ser obtida caso (i) a mão de obra terceirizada seja mais eficiente (eficiência obtida por especialização, gestão etc.) ou (ii) a remuneração dos trabalhadores terceirizados seja menor do que a que seria recebida caso o mesmo trabalhador fosse contratado diretamente. Essa segunda possibilidade é, inclusive, frequentemente utilizada como 
argumento por entidades sindicais e alguns setores da sociedade brasileira (CUT 2014; CNBB 2015) para justificar posições contrárias à regulamentação da terceirização. Os resultados apresentados nas seções seguintes desmontam esse argumento ao indicar que, quando se leva em conta as características observáveis e não observáveis (mas fixas no tempo) dos trabalhadores, os diferenciais são significativamente menores. Além disso, há fortes evidências de que, em linha com o argumentado nos parágrafos acima, os diferenciais salariais variam conforme a atividade terceirizada.

\section{Dados}

Este estudo utiliza a base de dados da Relação Anual de Informações Sociais (RAIS) para os anos de 2007 a 2014. A RAIS é compilada pelo Ministério do Trabalho e Emprego (MTE) anualmente desde 1975, e contém informações detalhadas sobre todos os vínculos de emprego registrados no Brasil, já que todas as pessoas jurídicas, inclusive a Administração Pública, devem enviar as informações referentes ao contrato de trabalho (salário, data de início do vínculo, afastamentos, desligamentos etc.) e também informar características sociodemográficas de cada trabalhador (idade, escolaridade, raça/cor, gênero etc.). O MTE disponibiliza publicamente os microdados da RAIS, porém sem a identificação dos indivíduos. A base de dados que utilizamos (também fornecida pelo MTE), porém, é ligeiramente diferente porque contém variáveis que permitem a identificação do mesmo indivíduo ao longo do tempo. A seção seguinte ilustra a importância dessa possibilidade de acompanhamento dos trabalhadores ao longo dos anos. Para construir a base de dados para este estudo, mantivemos apenas os trabalhadores que tinham um único vínculo ativo em 31 de dezembro de cada ano. Além disso, utilizamos apenas as informações dos vínculos ativos no final do ano, ou seja, caso tenha havido mais de uma mudança de emprego ao longo do ano, essa informação não foi utilizada. Também excluímos os registros nos quais o salário por hora registrado era inferior ao salário mínimo por hora vigente.

A identificação dos trabalhadores terceirizados não é possível diretamente. Esse talvez seja, inclusive, um dos principais motivos que justificam a ausência de trabalhos empíricos sobre o tema. De forma semelhante a Dube e Kaplan (2010), adotamos um procedimento que permite identificar in- 
diretamente quem são os trabalhadores terceirizados em determinadas ocupações. O método é simples e pode ser dividido em três etapas.

Primeiro, definimos ${ }^{3}$ um conjunto de ocupações que são tipicamente terceirizáveis, tais como: Porteiros, vigias e afins; Operadores de telemarketing; Trabalhadores nos serviços de manutenção de edificações (que inclui, entre outros, faxineiros) etc. Segundo, definimos atividades econômicas que são tipicamente de empresas prestadoras de serviços de terceirização de mão de obra, como por exemplo, Atividades de vigilância, segurança privada e transporte de valores; Atividades de limpeza etc. Finalmente, cruzamos os dois conjuntos de classificações anteriores e identificamos os trabalhadores em ocupações tipicamente terceirizáveis que trabalhavam em empresas cuja atividade é a prestação de serviços de terceirização. Esses trabalhadores foram então classificados como terceirizados em nossa base de dados. No anexo ao final do artigo foram listadas todas as ocupações e setores considerados. Além disso, também consideramos o código de atividade 829 (Outras atividades de serviços prestados principalmente às empresas) como atividade típica de empresas prestadoras de serviços terceirizados (desde que a ocupação do trabalhador coincida com as listadas anteriormente).

Um exemplo pode ajudar na compreensão do método. Suponha que identificamos na base da RAIS em um dado ano um indivíduo que trabalha na ocupação de vigia. Se esse trabalhador for contratado por uma empresa cuja atividade econômica é, por exemplo, Fabricação de calçados ou Comércio varejista, então segundo o critério de classificação proposto esse trabalhador não é terceirizado. Por outro lado, se o ramo de atividade da empresa em que esse vigia trabalha for Atividades de vigilância, segurança privada e transporte de valores, então esse indivíduo é classificado como terceirizado.

Há dois tipos de erro que podem ser cometidos com o procedimento descrito acima. Primeiro, podemos classificar um trabalhador como próprio que na verdade é terceirizado por uma empresa cuja atividade principal não é a de prestação de serviços terceirizados. Segundo, podemos classificar um trabalhador próprio de uma empresa de terceirização de mão de obra como terceirizado (como um vigia que cuida da segurança da

3 Os tipos de trabalho terceirizados foram adaptados de CNI (2014). A compatibilização CBO-CNAE foi feita pelos autores deste estudo e está disponível nos anexos. 
sede da empresa). Acreditamos que os dois casos devem representar uma parcela muito pouco significativa da base de dados.

A Tabela 1 lista os seis tipos de atividades terceirizáveis considerados neste estudo, e mostra a quantidade de trabalhadores em cada uma delas. Para identificar os terceirizados, utilizamos a Classificação Brasileira de Ocupações (CBO) no nível da família ocupacional (4 dígitos) e a Classificação Nacional de Atividades Econômicas (CNAE) no nível de grupos de atividade (3 dígitos). Reconhecemos que a classificação que este estudo adota não inclui a totalidade de ocupações terceirizáveis (ocupações como recepcionistas e serviços como jardinagem, por exemplo, não foram considerados). Cabe lembrar que não há uma definição precisa das ocupações "terceirizáveis", o que dificulta a classificação do que é ou não é "terceirizável". A única distinção que dispomos é a do TST, que divide as atividades "fim" das atividades "meio", que, em vista da discussão teórica apresentada e da atual configuração do mercado de trabalho no mundo, é uma classificação extremamente vaga e superada. Nesse sentido, a generalização dos resultados que serão apresentados nas próximas seções deve ser feita com cautela. Além disso, também foram excluídos das bases os indivíduos que transitaram entre as ocupações analisadas (por exemplo, um trabalhador que apareceu em um dado momento em atividades de limpeza e em outro ano em atividades de vigilância). Ao final do processo de montagem da base de dados havia 13.706.216 indivíduos diferentes ao longo dos oito anos disponíveis. Note-se que o painel não é balanceado, já que $49,5 \%$ dos indivíduos apareceram em apenas um ano na base de dados e apenas $5 \%$ dos indivíduos permaneceram em todos os anos considerados.

De maneira geral, chama a atenção o fato de que a participação da mão de obra terceirizada no conjunto das ocupações analisadas aumentou 1,3 pontos percentuais entre 2007 e 2014, atingindo 25,3\% do total da mão de obra nesse conjunto de ocupações. Esse percentual dá indícios de que a estimativa da CUT (2014) de que os terceirizados são 26,8\% do total do emprego formal em 2013 é superestimada, uma vez que mesmo entre as ocupações tipicamente terceirizáveis o percentual que encontramos é menor. Além disso, é interessante notar que a disseminação da terceirização é heterogênea: enquanto ocupações relacionadas a Montagem e manutenção de equipamentos tinham 5,4\% de terceirizados em 2014 (5,8\% em 2007), Telemarketing tinha $62,1 \%$ dos trabalhadores sendo contratados como terceirizados no mesmo ano (e 60,5\% em 2007). Em 2014, a base de dados 
tinha 3,9 milhões de indivíduos, ou 8\% de todo o emprego formal do Brasil naquele ano segundo o MTE.

Tabela 1 - Serviços consideradas para a análise da terceirização e suas participações no emprego formal do Brasil (2007/2014)

\begin{tabular}{|c|c|c|c|c|c|c|}
\hline \multirow[b]{2}{*}{ Serviços } & \multicolumn{3}{|c|}{2007} & \multicolumn{3}{|c|}{2014} \\
\hline & Terceiros & Próprios & $\%$ Ter. & Terceiros & Próprios & $\%$ Ter. \\
\hline $\begin{array}{l}\text { MONTAGEM E MANUTENÇC̃O DE } \\
\text { EQUIPAMENTOS }\end{array}$ & 37.751 & 608.081 & $5,8 \%$ & 47.936 & 836.516 & $5,4 \%$ \\
\hline SEGURANÇA/VIGILÂNCIA & 334.863 & 829.529 & $28,8 \%$ & 423.780 & 1.006 .304 & $29,6 \%$ \\
\hline TECNOLOGIA DA INFORMAÇÃO & 54.981 & 173.481 & $24,1 \%$ & 127.622 & 212.674 & $37,5 \%$ \\
\hline LIMPEZA E CONSERVAÇÃo & 342.481 & 1.142 .870 & $23,1 \%$ & 512.410 & 1.734 .536 & $22,8 \%$ \\
\hline PESQUISA E DESENVOLVIMENTO & 2.530 & 27.273 & $8,5 \%$ & 4.256 & 43.797 & $8,9 \%$ \\
\hline TELEMARKETING & 133.347 & 87.032 & $60,5 \%$ & 226.281 & 138.026 & $62,1 \%$ \\
\hline TOTAL & 905.953 & 2.868 .266 & $24,0 \%$ & 1.342 .285 & 3.971 .853 & $25,3 \%$ \\
\hline
\end{tabular}

Fonte: RAIS (MTE). Elaboração própria.

A Tabela 2 exibe algumas estatísticas descritivas da base de dados. Inicialmente, notamos que os trabalhadores terceirizados ganham, em média, menos do que os trabalhadores próprios. As demais estatísticas mostram, porém, que a comparação dos salários médios desses dois grupos de empregados deve ser feita com cautela, uma vez que há diferenças nos valores médios de variáveis importantes para a determinação da remuneração do trabalhador. Por exemplo, os terceirizados são, em média, três anos mais novos e ficam menos tempo no emprego. Há também diferenças significativas na proporção de mulheres e de trabalhadores brancos entre os grupos. Com as diferenças encontradas, é natural que a remuneração média observada dos terceirizados seja menor. A questão relevante é se as diferenças das características observáveis são suficientes para explicar toda a diferença nos salários nessas duas formas de contratação. 
Tabela 2 - Estatísticas descritivas

\begin{tabular}{|c|c|c|c|c|c|c|c|c|}
\hline \multirow[b]{2}{*}{ Variável } & \multicolumn{4}{|c|}{ Terceirizados } & \multicolumn{4}{|c|}{ Próprios } \\
\hline & Média & DP & Mín. & Máx. & Média & DP & Mín. & Máx. \\
\hline REMUNERAÇÃO MÉDIA* & 1.110 & 1.604 & 79,28 & 104.802 & 1.418 & 2.085 & 79,26 & 108.425 \\
\hline IDADE & 36 & 10,8 & 18 & 101 & 39 & 11,81 & 18 & 110 \\
\hline HORAS CONTRATADAS & 41,55 & 5,11 & 1 & 44 & 41,52 & 4,94 & 1 & 44 \\
\hline MULHERES & 0,4238 & - & 0 & 1 & 0,3499 & - & 0 & 1 \\
\hline BRANCO & 0,4988 & - & 0 & 1 & 0,5784 & - & 0 & 1 \\
\hline ENSINO MÉDIO & 0,5126 & - & 0 & 1 & 0,4792 & - & 0 & 1 \\
\hline ENSINO SUPERIOR & 0,0687 & - & 0 & 1 & 0,0714 & - & 0 & 1 \\
\hline TEMPO NO EMPREGO (MESES) & 35,08 & 44,51 & 0 & 599,3 & 71,49 & 84,01 & 0 & 600 \\
\hline NÚMERO DE DIAS AFASTADO & 4,12 & 25,27 & 0 & 432 & 3,82 & 24,49 & 0 & 970 \\
\hline DESLIGADO A PEDIDO & 0,0120 & - & 0 & 1 & 0,0056 & - & 0 & 1 \\
\hline ANO $=2007$ & 0,0996 & - & 0 & 1 & 0,1017 & - & 0 & 1 \\
\hline ANO $=2008$ & 0,1103 & - & 0 & 1 & 0,1134 & - & 0 & 1 \\
\hline ANO $=2009$ & 0,1137 & - & 0 & 1 & 0,1174 & - & 0 & 1 \\
\hline ANO $=2010$ & 0,1224 & - & 0 & 1 & 0,1257 & - & 0 & 1 \\
\hline ANO $=2011$ & 0,1306 & - & 0 & 1 & 0,1289 & - & 0 & 1 \\
\hline ANO $=2012$ & 0,1339 & - & 0 & 1 & 0,1343 & - & 0 & 1 \\
\hline ANO $=2013$ & 0,1420 & - & 0 & 1 & 0,1379 & - & 0 & 1 \\
\hline ANO $=2014$ & 0,1476 & - & 0 & 1 & 0,1408 & - & 0 & 1 \\
\hline TOTAL DE OBSERVAÇÕES & \multicolumn{4}{|c|}{9.096 .351} & \multicolumn{4}{|c|}{28.214 .658} \\
\hline
\end{tabular}

Fonte: RAIS (MTE). Elaboração própria.

$\left({ }^{*}\right)$ Salário mensal em 31/dezembro de cada ano corrigido pelo IPCA para dezembro de 2014.

\section{Metodologia e modelo econométrico}

O experimento ideal para identificar o efeito da terceirização sobre o salário seria comparar o salário de um empregado na situação de terceirizado e o salário deste mesmo empregado na condição de próprio ao mesmo tempo. Como isso não é possível, uma alternativa é comparar o empregado terceirizado com indivíduos próprios que sejam o mais parecido possível com ele em todas as características que afetem ao mesmo tempo o salário e a chance de ele ser ou não terceirizado. 
O painel da RAIS nos permite fazer essa comparação controlando o diferencial por características observáveis (idade, atividade, escolaridade e etc.), por características não observáveis fixas no tempo (habilidades cognitivas e não cognitivas, preferências e etc.) e também pelas diferentes tendências da evolução salarial dos indivíduos terceirizados e próprios. Para isso, a estratégia empírica utiliza modelos com efeito fixo dos indivíduos. Abordagem similar pode ser encontrada, por exemplo, em Botelho e Ponczek (2011), que estimam modelos com efeito fixo para avaliar o diferencial de salários entre trabalhadores formais e informais. Partimos da seguinte equação:

$$
w_{i t}=\alpha_{0}+\delta o_{i t}+\beta x_{i t}+\mu_{i}+e_{i t}
$$

onde $w_{i}$ é o logaritmo natural do salário (real) do indivíduo $i, o_{i t}$ é uma variável binária que assume valor um caso o trabalhador $i$ seja terceirizado no instante $t, x_{i t}$ é um vetor de covariadas observáveis relacionadas ao indivíduo $i$ no instante $t$ que, em nosso caso, inclui dummies de ano (para controlar por eventuais tendências nos salários comuns a todos os indivíduos), dummies relacionadas ao tamanho do estabelecimento, dummies do setor de atividade, o número de horas contratadas, dummies para o grau de instrução (para controlar mudanças na escolaridade dos trabalhadores ao longo do tempo) ${ }^{4}$, a duração do vínculo de trabalho em meses, seis dummies que controlam para os seis grupos de atividades de interesse e o número de dias nos quais o trabalhador ficou afastado no ano $t$, além de uma dummy que assume valor um no caso do empregado ter se desligado de seu último emprego por iniciativa própria e zero caso contrário. Por fim, $\mu_{i}$ é o efeito fixo do indivíduo $i$ (potencialmente correlacionado com $o_{i t}$ ) que captura características não observáveis e que não variam ao longo do tempo (habilidade, preferências etc.), enquanto $e_{i t}$ é erro.

Como notam Botelho e Ponczek (2011), o estimador de efeito fixo é consistente mesmo quando há um potencial viés de seleção, desde que as características não observáveis que são correlacionadas tanto com o salário quanto com a probabilidade de ser terceirizado sejam constantes ao longo do tempo. O modelo explicitado na Equação (1) pode, portanto, ser viesado se o efeito das características não observáveis na probabilidade de ser terceirizado e nos salários não for fixo no tempo. Para tentar contornar esse possível problema, também será estimada a seguinte equação:

${ }^{4}$ Cerca de $10 \%$ dos trabalhadores registram mudança nessa variável ao longo dos 4 anos de painel. 


$$
w_{i t}=\alpha_{0}+\delta o_{i t}+\beta x_{i t}+\sum_{t} \varphi_{t} o_{i}^{1} d_{t}+\mu_{i}+e_{i t}
$$

onde adicionamos o termo $o_{i}^{1}$, que é o valor de $o_{i t}$ na primeira observação do indivíduo $i$. O somatório permite que controlemos por tendências de salários eventualmente diferentes ao longo do tempo entre aqueles que inicialmente são terceirizados ou próprios. Assim, o efeito da terceirização medido por $\delta$ é aquele para além da tendência média de tipo de contratação.

Com essa especificação, a hipótese de identificação da Equação (2) é a de que a probabilidade de um indivíduo se tornar terceirizado é independente das características não observadas que não são fixas no tempo e que não foram incorporadas na tendência dos salários médios dos terceirizados e dos próprios. Deve-se notar que as variáveis que são fixas no tempo e observáveis, como por exemplo raça ou gênero, estão incorporadas no efeito fixo individual e por isso não aparecem explicitas nas equações acima.

Além disso, também chamamos a atenção para o fato de que a identificação só é possível porque há indivíduos que transitam entre terceirização e contratação própria ao longo do tempo. A Tabela 3 mostra a matriz de transição entre a condição de contratação direta e a terceirização. Notase que $7,6 \%$ dos trabalhadores que eram terceirizados em um dado ano assumem uma condição de contratação direta no ano seguinte. Por outro lado, apenas $2,2 \%$ dos contratados diretamente tornam-se terceirizados no ano seguinte.

Tabela 3 - Transições de e para a terceirização

\begin{tabular}{cccc}
\hline & \multicolumn{3}{c}{ Tipo de contratação no ano seguinte } \\
\cline { 2 - 4 } Tipo de contratação no ano inicial & TERCEIRIZADO & NÃO TERCEIRIZADO & NúMERO DE OBSERVAÇõES \\
\hline TERCEIRIZADO & $92,4 \%$ & $7,6 \%$ & 5.558 .994 \\
NÃO TERCEIRIZADO & $2,2 \%$ & $97,8 \%$ & 18.045 .807 \\
NÚMERO DE OBSERVAÇÕES & 5.536 .509 & 18.068 .292 & 23.604 .801 \\
\hline
\end{tabular}

Fonte: RAIS 2007 a 2014 (MTE). Elaboração própria. 
Ou seja, os resultados que serão apresentados medem o diferencial de salários para aqueles que transitam entre as condições de terceirizado e próprio e a generalização dos resultados para todos os trabalhadores não é, necessariamente, imediata.

Além do diferencial médio entre terceirizados e próprios, também exploramos a heterogeneidade dessa diferença em três dimensões distintas: ocupacional, temporal (referente a efeitos heterogêneos entre os anos) e na direção da transição entre a condição de contratação. Em todos os casos, acrescentamos à Equação (1) interações entre a dummy de terceirização $o_{i t}$ e as variáveis que capturam a dimensão de interesse. As equações estimadas são:

$$
w_{i t}=\alpha_{0}+\delta o_{i t}+\sum_{m-1} \emptyset_{m} o_{i t} h_{i m}+\beta x_{i t}+\mu_{i}+e_{i t}
$$

onde $h_{\text {im }}$ representa as variáveis para as quais desejamos obter os efeitos heterogêneos, que serão dados por $\delta+\emptyset_{m}$. Na equação acima, $m$ representa as diferentes categorias de cada variável. Por exemplo, no caso das ocupações, são seis categorias diferentes e, portanto, cinco coeficientes $\emptyset_{m}$ a serem estimados (já que uma das categorias será a referência).

\section{Resultados}

Nesta seção serão apresentados os resultados da estimação dos modelos anteriormente discutidos. A seção se divide em duas subseções. Na primeira delas, apresentamos as estimativas do diferencial médio da terceirização no salário dos empregados. Na segunda subseção, são apresentados os resultados das regressões que buscam captar efeitos heterogêneos da terceirização.

\subsection{Diferencial médio da terceirização}

A Tabela 4 exibe os resultados para a estimativa do diferencial de salários entre os terceirizados e os diretamente contratados. A primeira coluna mostra o coeficiente estimado por meio da regressão de $w$ em uma cons- 
tante e na variável dummy de terceirização. Como esperado, o diferencial (não condicional) é bastante negativo $(-16,7 \%)$. Já a segunda coluna da mesma tabela mostra que o diferencial de salários fica ainda mais negativo $(-18,3 \%)$ quando controlamos por características observáveis.

Por outro lado, a terceira coluna da Tabela 4 apresenta os resultados da estimação da Equação (1) e nos leva a uma conclusão diferente a respeito do diferencial de salários entre os terceirizados e os trabalhadores próprios. A diferença média na remuneração de um mesmo indivíduo que muda de emprego e transita de uma forma de contratação para a outra é de $-3,6 \%$. Essa diferença é consideravelmente menor do que a encontrada nos dois exercícios anteriores. A última coluna exibe o resultado do modelo descrito pela Equação (2), quando se leva em conta possíveis diferenças nas trajetórias dos salários dos empregados terceirizados e próprios. O resultado encontrado é estatisticamente o mesmo da coluna anterior, o que parece dar indícios de que o efeito das trajetórias não parece ser relevante.

Tabela 4 - Efeitos da terceirização nos salários

\begin{tabular}{|c|c|c|c|c|}
\hline & MQO (sem controles) & MQO (com controles) & $\begin{array}{l}\text { Efeito fixo } \\
\text { (Eq. 1) }\end{array}$ & $\begin{array}{c}\text { Efeito fixo e tendência } \\
\text { (Eq. 2) }\end{array}$ \\
\hline \multirow{2}{*}{$\delta$} & $-0,1672^{\star \star *}$ & $-0,1833^{\star \star *}$ & $-0,0365^{\star \star \star}$ & $-0,0355^{\star \star \star}$ \\
\hline & $(0,0003)$ & $(0,0003)$ & $(0,0006)$ & $(0,0006)$ \\
\hline Observações & 37.311 .009 & 27.906 .734 & 34.708 .143 & 34.708 .143 \\
\hline Indivíduos & - & - & 13.375 .996 & 13.375 .996 \\
\hline $\mathrm{R}^{2}$ (ajustado/total) & 0,0084 & 0,6801 & 0,2720 & 0,2734 \\
\hline
\end{tabular}

Fonte: RAIS 2007-2014 (MTE). Elaboração própria.

Nota 1: Erros padrões entre parênteses. A regressão estimada via MQO sem controles tem o logaritmo do salário real como variável dependente e apenas uma constante e a dummy 'terceirizado' como regressores; a regressão com controles utiliza também dummies de UF, setor, família ocupacional, setor de atividade, gênero, cor, nível de escolaridade, tamanho do estabelecimento e ano, além de idade, horas contratadas e número de dias de afastamento.

Nota 2: A remuneração em 31/dezembro de cada ano foi corrigida pelo IPCA para dezembro de 2014.

${ }^{*}$ significativo a $10 \% ;{ }^{* *}$ significativo a $5 \% ;{ }^{* * *}$ significativo a $1 \%$. 


\subsection{Efeitos heterogêneos}

Identificado o diferencial médio, buscamos nessa subseção responder se esse diferencial é heterogêneo entre as seguintes três dimensões: ocupacional, temporal (referente a efeitos heterogêneos entre os anos) e na direção da transição entre a condição de contratação. Em todas as regressões controlamos os efeitos apenas por características observáveis e não observáveis fixas no tempo. Essa opção levou em conta o fato de que, conforme evidenciado na Tabela 4, o controle de tendência parece não alterar os resultados em relação ao modelo de efeito fixo, além de evitar uma complexidade grande nas especificações de cada nova estimação. Ou seja, partiremos da Equação (1) e acrescentaremos parâmetros que nos permitam identificar a eventual heterogeneidade do diferencial, como ilustrado na Equação (3).

É plausível que o impacto da terceirização não seja homogêneo em todo mercado de trabalho. Quando expusemos os argumentos teóricos que levariam à segmentação do mercado de trabalho entre trabalhadores terceirizados e próprios, notamos que aspectos institucionais do mercado de trabalho poderiam explicar esse fenômeno. O que faria um trabalhador aceitar um salário mais baixo na condição de terceirizado? Uma explicação bastante razoável seria uma diferença no poder de barganha do trabalhador. Por exemplo, trabalhadores próprios podem ser representados por sindicatos de categoria diferente à dos terceirizados, e então diferentes condições de negociação de acordos e convenções coletivas surgiriam. Imaginemos um vigia que resida na região do $A B C$ Paulista, que tradicionalmente abriga muitas indústrias do setor de autopeças. Caso seja terceirizado, esse vigia deixará de ser representado pelo Sindicato dos Metalúrgicos do $\mathrm{ABC}$, uma instituição tradicionalmente representativa e combativa. Nesse caso, as condições de negociação seriam afetadas e o impacto disso nos salários poderia ser negativo. 
Tabela 5 - Efeitos da terceirização nos salários de acordo com as ocupações terceirizadas

\begin{tabular}{|c|c|c|}
\hline Ocupação & Coeficiente & Efeito fixo (Equação 3) \\
\hline MONTAGEM E MANUTENÇÃO DE EQUIPAMENTOS & $\delta$ & $\begin{array}{c}-0,0594^{\star * *} \\
(0,0017)\end{array}$ \\
\hline SEGURANÇA/VIGILÂNCIA & $\delta+\emptyset_{S V}$ & $\begin{array}{l}0,0494^{* * *} \\
(0,0009)\end{array}$ \\
\hline TECNOLOGIA DA INFORMAÇÃO & $\delta+\emptyset_{T I}$ & $\begin{array}{c}-0,0548^{* * *} \\
(0,0020)\end{array}$ \\
\hline LIMPEZA E CONSERVAÇÃo & $\delta+\emptyset_{L}$ & $\begin{array}{c}-0,0595^{\star \star \star} \\
(0,0005)\end{array}$ \\
\hline PESQUISA E DESENVOLVIMENTO & $\delta+\emptyset_{P \& D}$ & $\begin{array}{c}-0,0247^{\star * *} \\
(0,0084)\end{array}$ \\
\hline TELEMARKETING & $\delta+\emptyset_{T M}$ & $\begin{array}{c}-0,0881^{\star * *} \\
(0,0017)\end{array}$ \\
\hline Observações & & 34.708 .234 \\
\hline Indivíduos & & 13.375 .996 \\
\hline $\mathrm{R}^{2}$ (ajustado/total) & & 0,2723 \\
\hline
\end{tabular}

Fonte: RAIS 2007-2014 (MTE). Elaboração própria. Nota: Erros padrões entre parênteses.

${ }^{*}$ significativo a $10 \% ;{ }^{* *}$ significativo a $5 \%$; ${ }^{* *}$ significativo a $1 \%$.

A Tabela 5 mostra os efeitos para cada uma das ocupações consideradas no estudo. Para encontrar o diferencial total somamos o coeficiente associado à dummy terceirização com o coeficiente da interação entre terceirização e ocupação (exceto no caso da categoria de referência, Montagem e manutenção de equipamentos).

O maior diferencial nos salários foi encontrado para os trabalhadores de Telemarketing que transitam entre as duas formas de contratação com -9\% no salário mensal. Trabalhadores de Limpeza e conservação, Montagem e manutenção de equipamentos e TI também apresentam um diferencial negativo, todos entre $-5,5 \%$ e $-6 \%$. Já os trabalhadores envolvidos em atividades de $\mathrm{P} \& \mathrm{D}$ tem um diferencial médio próximo a $-2,5 \%$. Por outro lado, os trabalhadores das atividades de Segurança/vigilância recebem, em média, $4,9 \%$ a mais quando são terceirizados. 
O exercício com as ocupações evidencia que existe uma considerável heterogeneidade no diferencial de salário entre empregados terceirizados e próprios conforme as ocupações consideradas. O efeito médio, incondicional a ocupações, é negativo e relativamente pequeno, mas dentro dele encontram-se desde efeitos negativos relativamente mais altos (Telemarketing) até efeitos positivos, como no caso das ocupações de Segurança/Vigilância.

Consideramos também a possibilidade de que o efeito da terceirização possa ser heterogêneo entre os anos. Por exemplo, é possível que o diferencial de salário entre os dois tipos de empregados aumente ou diminua conforme as condições macroeconômicas. Durante uma crise econômica, as empresas tendem a reduzir despesas e aumentar a eficiência. Uma hipótese razoável é que isso pode levar elas a substituir trabalhadores próprios pela contratação de empresas terceirizadas que desempenhem o mesmo serviço a um custo menor.

A Tabela 6 e o Gráfico 1 mostram os efeitos médios da terceirização por ano. O efeito médio é negativo em todos os anos, mas não é homogêneo ao longo do período analisado. O efeito cresce em módulo, partindo de -1\% em 2007 até atingir o valor mais negativo em 2011. A partir de 2012 o diferencial começa a cair e chega em $-1,6 \%$ no ano 2014. De fato, como explorado no parágrafo anterior, o mercado de trabalho brasileiro experimentou um período de grande dinamismo em boa parte do período aqui analisado e, além disso, o final do período foi marcado pela desoneração da folha de pagamentos (especialmente depois de 2012). Isso pode, talvez, explicar a dinâmica do diferencial ao longo de tempo. Mas, certamente, essa é uma questão que demanda maior investigação em futuros trabalhos.

Uma terceira dimensão que consideramos para avaliar a heterogeneidade diz respeito à direção da mudança da condição de contratação. Avaliaremos se o diferencial muda de acordo com a condição inicial dos trabalhadores, isto é, se a perda na remuneração é diferente quando um terceirizado se torna próprio e vice-versa. Para isso, separamos a amostra original segundo a direção da transição, que pode ser 'Próprio $\rightarrow$ Terceirizado' ou 'Terceirizado $\rightarrow$ Próprio'. Ou seja, estimamos o modelo de efeito fixo separadamente para duas subamostras: (a) uma composta por todos os indivíduos que são próprios durante todo o período e pelos indivíduos que inicialmente eram próprios mas que transitaram para a condição de terceirizado e (b) uma composta por todos os indivíduos que foram terceirizados longo do tempo e pelos indivíduos que inicialmente eram terceirizados, mas que transitaram para a condição de próprios em algum momento. 
Tabela 6 - Efeitos da terceirização nos salários ao longo dos anos

\begin{tabular}{|c|c|}
\hline Anos & Efeito fixo \\
\hline \multirow{2}{*}{2007} & $-0,01018^{* * \star}$ \\
\hline & $(0,00059)$ \\
\hline \multirow{2}{*}{2008} & $-0,02774^{* \star *}$ \\
\hline & $(0,00055)$ \\
\hline \multirow{2}{*}{2009} & $-0,04207^{* * *}$ \\
\hline & $(0,00054)$ \\
\hline \multirow{2}{*}{2010} & $-0,04427^{\star \star *}$ \\
\hline & $(0,00052)$ \\
\hline \multirow{2}{*}{2011} & $-0,04706^{* * *}$ \\
\hline & $(0,00057)$ \\
\hline \multirow{2}{*}{2012} & $-0,04343^{* * *}$ \\
\hline & $(0,00052)$ \\
\hline \multirow{2}{*}{2013} & $-0,01656^{* * *}$ \\
\hline & $(0,00054)$ \\
\hline \multirow{2}{*}{2014} & $-0,01627^{\star * *}$ \\
\hline & $(0,00056)$ \\
\hline Observações & 34.708 .234 \\
\hline Indivíduos & 13.375 .996 \\
\hline $\mathrm{R}^{2}$ (ajustado/total) & 0,2683 \\
\hline
\end{tabular}

Fonte: RAIS 2007-2014 (MTE). Elaboração própria. Nota: Erros padrões entre parênteses.

${ }^{*}$ significativo a $10 \% ;{ }^{* *}$ significativo a $5 \%$; ${ }^{* *}$ significativo a $1 \%$.

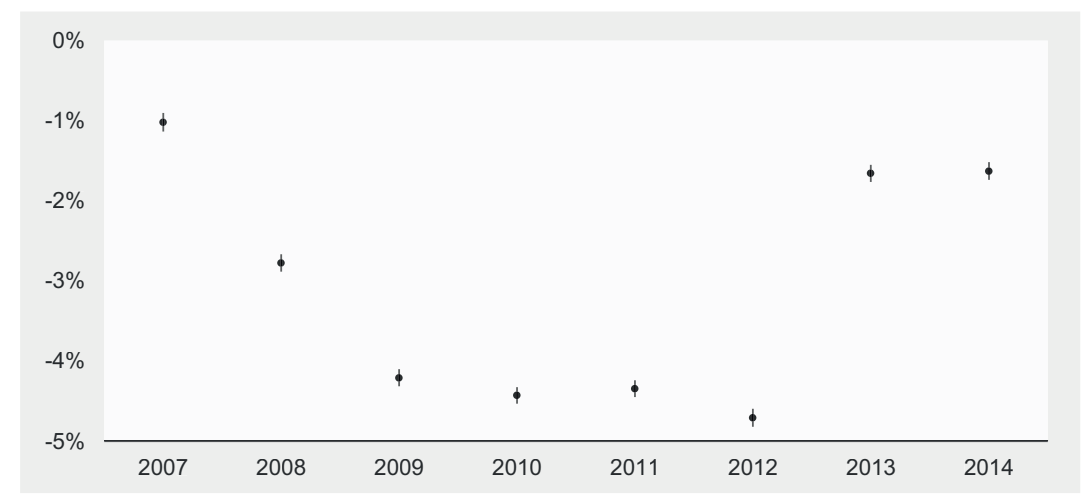

\section{Gráfico 1 - Efeitos da terceirização nos salários ao longo dos anos}

Fonte: RAIS 2007-2014 (MTE). Elaboração própria. Nota: As linhas verticais representam o intervalo de confiança a 95\%.

${ }^{*}$ significativo a $10 \%$; ${ }^{* *}$ significativo a $5 \%$; ${ }^{* *}$ significativo a $1 \%$. 
Os resultados apresentados na Tabela 7 mostram que a magnitude da perda de remuneração dos terceirizados depende da direção da transição. Para os próprios que se tornam terceirizados, a diferença salarial média é de $-2,5 \%$. Já para os terceirizados que se tornam próprios, a diferença salarial é de $-4,5 \%$. Ou seja, em média, o aumento do salário de um terceirizado que se torna próprio é maior (em módulo) do que a perda de salário de um próprio que se torna terceirizado. Por que essa disparidade nas magnitudes? Candidatos naturais à explicação seriam, por exemplo, um possível efeito estigma ou um ajuste hedônico diferente dos salários. Há diversas explicações possíveis, mas, novamente, não faz parte do escopo deste trabalho aprofundar essa investigação - que também fica em aberto para futuros trabalhos.

Tabela 7 - Efeitos da terceirização nos salários

\begin{tabular}{cccc}
\hline & Próprio $\rightarrow$ Terceirizado & & Terceirizado $\rightarrow$ Próprio \\
\cline { 2 - 3 }$\delta$ & $-0,02339^{\star \star *}$ & & $-0,04542^{\star \star \star}$ \\
Observações & $(0,0011)$ & $(0,0010)$ \\
\hline Indivíduos & 25.794 .068 & 7.857 .940 \\
\hline $\mathrm{R}^{2}$ (ajustado/total) & 9.789 .917 & 3.306 .056 \\
\hline
\end{tabular}

Fonte: RAIS 2007-2014 (MTE). Elaboração própria.

Nota 1: Erros padrões entre parênteses.

Nota 2: A remuneração em 31/dezembro de cada ano foi corrigida pelo IPCA para dezembro de 2014.

${ }^{*}$ significativo a $10 \% ;{ }^{* *}$ significativo a $5 \% ;{ }^{* * *}$ significativo a $1 \%$.

\section{Conclusões e considerações finais}

Este trabalho estima o diferencial de salários entre a mão de obra terceirizada e os trabalhadores contratados diretamente pelas empresas tomadoras dos serviços. Antes de enfrentar o desafio empírico, o texto faz algumas considerações teóricas, valendo-se de Becker e Coase para interpretar e explicar as transformações profundas que ocorrem no momento no mercado de trabalho mundial. O texto coloca a emergência e a ampliação da terceirização nessa perspectiva teórica. As ocupações ou serviços considerados para a análise foram Montagem e manutenção de equipamentos, Segurança/ Vigilância, TI, Limpeza e conservação, P\&D e Telemarketing. 
Os resultados indicam que, numa comparação não condicional, os trabalhadores terceirizados recebem em média um salário $17 \%$ menor do que no caso em que a contratação é direta. O diferencial chega a 18\% quando controlado pelas características observáveis dos trabalhadores, mas diminui para 3,6\% quando controlado pelo efeito fixo dos indivíduos. $\mathrm{Ou}$ seja, os resultados indicam que as características não observáveis exercem um papel relevante na seleção e na determinação da remuneração dos terceirizados.

Outro fato importante é a heterogeneidade dos diferenciais. Por exemplo, ocupações como Telemarketing e Limpeza oferecem remunerações menores aos terceirizados. Porém, ocupações como Segurança e Vigilância apresentaram salários maiores para os empregados terceirizados. Efeitos heterogêneos também foram encontrados quando se leva em conta a dimensão temporal. O diferencial ficou mais negativo, em relação aos terceirizados, de 2007 até 2012 e, a partir de então ele foi se reduzindo.

A elaboração deste estudo se deu em meio a um importante debate na sociedade sobre a terceirização e seus efeitos. O principal argumento daqueles que se opõem à terceirização é o da precarização do trabalho. As evidências apresentadas neste trabalho não permitem corroborar essa hipótese (de precarização), ao menos em relação à remuneração mensal dos empregados. Porém, os resultados baseiam-se no salário em carteira informado através da RAIS (MTE) e, portanto, não levam em conta outros benefícios (pecuniários ou não). Também não são medidas diferenças entre as condições de trabalho nas duas formas de contratação (acesso a vestiário, banheiros, alimentação em restaurante etc.). De toda forma, os resultados são robustos e permitem avaliarmos algumas opções de políticas. Vale comentar também que os resultados são medidos nos salários e não há nenhum teste no número de empregos (i.e. efeito quantidade). É possível que nos serviços nos quais os salários dos terceirizados são menores, o nível do emprego seja maior exatamente porque o "preço" (salário) é menor.

Nosso artigo é um primeiro esforço com rigor estatístico para buscar compreender melhor os efeitos da terceirização no mercado de trabalho. Ele suscita uma série de questões para pesquisas futuras como, por exemplo, o que explicaria os efeitos heterogêneos encontrados entre ocupações e ao longo do tempo. Embora a compreensão desses fenômenos fuja do escopo deste trabalho, ela sem dúvida é de suma importância para a melhoria das políticas públicas no Brasil e, por esse motivo, encorajamos a busca de respostas. 


\section{Referências}

Becker, Gary. 1961. Human Capital. New York: National Bureau of Economic Research.

Botelho, Fernando, and Vladimir Ponczek. 2011. "Segmentation in the Brazilian Labor Market." Economic Development and Cultural Change 59 (2): 437 - 463.

Central Única dos Trabalhadores (CUT). 2014. "Terceirização e desenvolvimento: uma conta que não fecha: dossiê acerca do impacto da terceirização sobre os trabalhadores e propostas para garantir a igualdade de direitos." Secretaria Nacional de Relações de Trabalho e Departamento Intersindical de Estatística e Estudos Socioeconômicos. São Paulo.

Coase, Ronald H. 1937. “The nature of the firm.” Economica 4 (16): 386 - 405.

Confederação Nacional da Indústria (CNI). 2014. "Sondagem Especial: Terceirização." Sondagem Especial 4 (2).

Confederação Nacional dos Bispos do Brasil (CNBB). 2015. "Nota da CNBB sobre o momento nacional." 53a Assembleia Geral da CNBB. Acesso 11 Junho, 2015. http://www.cnbb.org.br/eventos-1/assembleia-geral-1/16376cnbb-divulga-nota-sobre-o-momento-nacional.

Doeringer, Peter B., and Michael J. Piore. 1971. Internal Labor Markets and Manpower Analysis. Lexington: Heath.

Dube, Arindrajit, and Ethan Kaplan. 2010. "Does Outsourcing Reduce Wages in the Low-Wage Service Occupations? Evidence from Janitors and Guards." Industrial and Labor Relations Review 63 (2): 287- 306. Cornell University, ILR School.

Eichhorst, Werner. 2015. "Do We Have to Be Afraid of the Future World of Work?" IZA Policy Papers 102. Institute for the Study of Labor (IZA).

Eurofound. 2015. "New forms of employment." Luxembourg: Publications Office of the European Union.

Heckman, James J. , and Yona Rubinstein. 2001. "The importance of Noncognitive Skills: Lessons from the GED Testing Program.” The American Economic Review 91 (2): 145 - 149.

Heckman, James J., Jora Stixrud and Sergio Urzua. 2006. "The Effects of Cognitive and Noncognitive Abilities on Labor Market Outcomes and Social Behavior." Journal of Labor Economics 24 (3): 411 - 482. http://www. nber.org/papers/w12006.pdf.

Menezes Filho, Naércio Aquino, Marcos Mendes and Eduardo Simões de Almeida. 2004. "O diferencial de salários formal-informal no Brasil: segmentação ou viés de seleção?” Revista Brasileira de Economia 58 (2): 235 - 248.

Zimmermann, Klaus F. 2015. "The Big Trade-Off in the World of Labor." IZA Policy Papers 100. Institute for the Study of Labor (IZA).

Zylberstajn, Hélio. 2010. "The end of jobs: a case of theoretical convergence?" The International Journal of Comparative Labour Law and Industrial Relations 26 (4): 389 - 400.

Zylberstajn, Hélio. 2015. "Uma interpretação econômica para a crise do paradigma." In A Valorização do Trabalho Autônomo e a Livre Iniciativa, edited by Yone Frediane, 65 - 72. Porto Alegre: Lex Magister. 


\section{Anexo}

\section{Códigos $\mathrm{CBO}$ considerados para a definição de terceirização}

\section{Montagem e manutenção de equipamentos}

\begin{tabular}{|c|c|}
\hline CBO & Descrição \\
\hline 1238 & Diretores de manutenção \\
\hline 9511 & Eletricistas de manutenção eletroeletrônica \\
\hline 1427 & Gerentes de manutenção e afins \\
\hline 9513 & Instaladores e mantenedores de sistemas eletroeletrônicos de segurança \\
\hline 7321 & Instaladores e reparadores de linhas e cabos elétricos, telefônicos e de comunicação de \\
\hline 7313 & Instaladores-reparadores de linhas e equipamentos de telecomunicações \\
\hline 9141 & Mecânicos de manutenção aeronáutica \\
\hline 9193 & Mecânicos de manutenção de bicicletas e equipamentos esportivos e de ginástica \\
\hline 9111 & Mecânicos de manutenção de bombas, motores, compressores e equipamentos de transmissão \\
\hline 9113 & Mecânicos de manutenção de máquinas industriais \\
\hline 9131 & Mecânicos de manutenção de máquinas pesadas e equipamentos agrícolas \\
\hline 9112 & Mecânicos de manutenção e instalação de aparelhos de climatização e refrigeração \\
\hline 7312 & Montadores de aparelhos de telecomunicações \\
\hline 7311 & Montadores de equipamentos eletroeletrônicos \\
\hline 7257 & Instaladores de equipamentos de refrigeração e ventilação \\
\hline 7252 & Montadores de máquinas industriais \\
\hline 7253 & Montadores de máquinas pesadas e equipamentos agrícolas \\
\hline 7251 & Montadores de máquinas, aparelhos e acessórios em linhas de montagem \\
\hline 7254 & Mecânicos montadores de motores e turboalimentadores \\
\hline 7202 & Supervisores da fabricação e montagem metal-mecânica \\
\hline 9501 & Supervisores de manutenção eletroeletrônica industrial, comercial e predial \\
\hline 9503 & Supervisores de manutenção eletromecânica \\
\hline 9101 & $\begin{array}{l}\text { Supervisores em serviços de reparação e manutenção de máquinas e equipamentos industriais, comerciais } \\
\text { e residenciais }\end{array}$ \\
\hline 9153 & Técnicos em manutenção e reparação de equipamentos biomédicos \\
\hline 9151 & Técnicos em manutenção e reparação de instrumentos de medição e precisão \\
\hline 3141 & Técnicos mecânicos na fabricação e montagem de máquinas, sistemas e instrumentos \\
\hline 3144 & Técnicos mecânicos na manutenção de máquinas, sistemas e instrumentos \\
\hline 9192 & Trabalhadores de manutenção de roçadeiras, motosserras e similares \\
\hline
\end{tabular}




\section{Segurança/Vigilância}

\begin{tabular}{ll}
\hline CBO & Descrição \\
\hline 5172 & Policiais, guardas-civis municipais e agentes de trânsito \\
\hline 5174 & Porteiros, vigias e afins \\
\hline 2526 & Profissionais da administração dos serviços de segurança \\
\hline 5103 & Supervisores dos serviços de proteção, segurança e outros \\
\hline 5173 & Vigilantes e guardas de segurança \\
\hline
\end{tabular}

TI

\begin{tabular}{ll}
\hline CBO & Descrição \\
\hline 2124 & Analistas de tecnologia da informação \\
\hline 1236 & Diretores de serviços de informática \\
\hline 2122 & Engenheiros em computação \\
\hline 2123 & Administradores de tecnologia da informação \\
\hline 1425 & Gerentes de tecnologia da informação \\
\hline 3171 & Técnicos de desenvolvimento de sistemas e aplicações \\
\hline
\end{tabular}

\section{Limpeza e conservação}

\begin{tabular}{cl}
\hline CBO & Descrição \\
\hline 5133 & Camareiros, roupeiros e afins \\
\hline 5143 & Trabalhadores nos serviços de manutenção de edificações \\
\hline 5142 & Trabalhadores nos serviços de coleta de resíduos, de limpeza e conservação de áreas públicas \\
\hline
\end{tabular}

\section{P\&D}

\begin{tabular}{ll}
\hline CBO & Descrição \\
\hline 1237 & Diretores de pesquisa e desenvolvimento \\
\hline 1426 & Gerentes de pesquisa e desenvolvimento e afins \\
\hline 2030 & Pesquisadores das ciências biológicas \\
\hline 2034 & Pesquisadores das ciências da agricultura \\
\hline 2033 & Pesquisadores das ciências da saúde \\
\hline 2031 & Pesquisadores das ciências naturais e exatas \\
\hline 2035 & Pesquisadores das ciências sociais e humanas \\
\hline 2032 & Pesquisadores de engenharia e tecnologia \\
\hline 3951 & Técnicos de apoio em pesquisa e desenvolvimento \\
\hline
\end{tabular}

\section{Telemarketing}

\begin{tabular}{ll} 
CBO & Descrição \\
\hline 4223 & Operadores de telemarketing
\end{tabular}




\section{Códigos CNAE considerados para a definição de terceirização}

Montagem e manutenção de equipamentos

\begin{tabular}{cl}
\hline CNAE & Descrição \\
\hline 331 & Manutenção e reparação de máquinas e equipamentos \\
\hline 332 & Instalação de máquinas e equipamentos \\
\hline 951 & Reparação e manutenção de equipamentos de informática e comunicação \\
\hline 952 & Reparação e manutenção de objetos e equipamentos pessoais e domésticos \\
\hline
\end{tabular}

\section{Segurança/Vigilância}

\begin{tabular}{cl}
\hline CNAE & Descrição \\
\hline 801 & Atividades de vigilância, segurança privada e transporte de valores \\
\hline
\end{tabular}

TI

\begin{tabular}{cl} 
CNAE & Descrição \\
\hline 620 & Atividades dos serviços de tecnologia da informação
\end{tabular}

\section{Limpeza e conservação}

\begin{tabular}{cl}
\hline CNAE & Descrição \\
\hline 811 & Serviços combinados para apoio a edifícios \\
\hline 812 & Atividades de limpeza \\
\hline 970 & Serviços domésticos \\
\hline
\end{tabular}

\section{P\&D}

\begin{tabular}{cl}
\hline CNAE & Descrição \\
\hline 721 & Pesquisa e desenvolvimento experimental em ciências físicas e naturais \\
\hline 722 & Pesquisa e desenvolvimento experimental em ciências sociais e humanas \\
\hline
\end{tabular}

\section{Telemarketing}

\begin{tabular}{cl}
\hline CNAE & Descrição \\
\hline 822 & Atividades de teleatendimento \\
\hline
\end{tabular}

